\title{
Diagnosis and management of osteoporosis in the older senior
}

\author{
Sheryl F Vondracek \\ Sunny A Linnebur
}

Department of Clinical Pharmacy, School of Pharmacy C238-LI5, University of Colorado Denver, Aurora, CO, USA
Correspondence: Sheryl FVondracek Associate Professor, Department of Clinical Pharmacy, School of Pharmacy C238-LI 5, University of Colorado Denver, I263I E 17th Ave,Aurora, CO 80045, USA

Tel +I 3037242638

Fax +l 3037240979

Email sheryl.vondracek@ucdenver.edu

\begin{abstract}
The older senior is at high risk for osteoporosis. It is important for healthcare providers to be fully aware of the potential risks and benefits of diagnosing and treating osteoporosis in the older senior population. Data indicate that bone mineral density testing is under-utilized and drug therapy is often not initiated when indicated in this population. Bone mineral density testing with central dual energy x-ray absorptiometry is essential and cost-effective in this population. All older seniors should be educated on a bone-healthy lifestyle including age-appropriate weightbearing exercise and smoking cessation if necessary. It is important to remember that falls play a very important role in the risk for osteoporotic fractures, especially in the older senior. All older seniors should be evaluated annually for falls and strategies should be implemented to reduce fall risk in this population. The risk for vitamin D insufficiency and deficiency is high in the older senior and can contribute to falls and fractures. Adequate intakes of calcium and vitamin D are important and deficiencies need to be treated. Data on osteoporosis drug therapy in the older senior are lacking. Based on data from subgroup analyses of large osteoporosis trials in postmenopausal women, current osteoporosis therapies appear safe and efficacious in the older senior and most will live long enough to derive a benefit from these therapies. Further studies are needed in older seniors, especially men, to better understand the risks and benefits of pharmacologic therapy for the management of osteoporosis.
\end{abstract}

Keywords: osteoporosis, aged, elderly, eighty and over, senior, diphosphonates

\section{Introduction}

Osteoporosis is, for the most part, a disease of aging. Age is an independent risk factor for the development of osteoporosis and osteoporotic fractures (low-trauma fractures) and the prevalence of osteoporosis rises dramatically with age. ${ }^{1}$ According to National Health and Nutrition Examination Survey (NHANES) data, the prevalence of osteoporosis based on reduced hip bone density was estimated at $4 \%$ in women 50 to 59 years of age compared to $44 \%$ in women 80 years of age and older. ${ }^{2,3}$ The number of seniors at risk for osteoporosis is going to continue to increase with the aging of society. It is estimated that the number of people in the United States (US) over the age of 65 years will increase from 36.8 million in 2004 to 54.6 million by $2020 .{ }^{4}$ During the same time period, the number of people age 85 years and older will increase from 5.1 million to 7.3 million. It has been estimated that in the US the number of hip fractures and their associated costs could double or triple by the year 2040. ${ }^{5}$ These statistics are similar worldwide. ${ }^{6}$

The risk for low-trauma fractures goes up substantially with age. Hip fracture risk, in particular, rises exponentially after age 70 years. ${ }^{7-9}$ In one study, the incidence rate for hip fractures was estimated at 1.6 per 1000 person-years for 65-year-old white women compared to 35.4 per 1000 person-years in 95-year-old women. ${ }^{9}$ In 2004, there were 329,000 hospital discharges for hip fracture with 125,000 occurring in patients $\geq 85$ years of age compared to 116,000 in patients 75 to 84 years of age and 48,000 in patients between 65 and 74 years of age. ${ }^{10}$ Low-trauma fractures, especially 
hip fractures, significantly increase health care costs, and contribute to an increase in morbidity and mortality in the older senior. ${ }^{11-16}$ After hip fracture, only half of patients return to their pre-fracture ability level. ${ }^{12}$ In addition, $3 \%$ to $5 \%$ of patients die during the initial hospitalization for hip fracture, and approximately $20 \%$ to $40 \%$ die within 1 year. ${ }^{12,17}$

Data indicate that older seniors with osteoporosis are frequently not treated with drug therapy. ${ }^{18-22}$ A prospective cross-sectional study of nursing home residents (average age $\sim 80$ years) with known osteoporosis or recent hip fracture revealed that $69 \%$ were receiving calcium and $63 \%$ vitamin D, but only $19 \%$ a bisphosphonate. ${ }^{23}$ Overall, only $36 \%$ were receiving any prescription medication or hip protector for osteoporosis. In a cross-sectional database analysis of newly admitted nursing facility residents $(79.6 \% \geq 75$ years of age and $36.6 \% \geq 85$ years of age), only $9.1 \%$ were receiving an antiresorptive agent or calcium and vitamin D supplementation despite an expected high prevalence of osteoporosis in this population. ${ }^{24}$ Osteoporosis medication use was evaluated in 4430 patients who sustained a hip, wrist or humeral fracture and were admitted to a nursing home from 1995 to $2004 .{ }^{19}$ Mean age of the study population was 82.7 years. Only $11.5 \%$ of patients received any type of osteoporosis medication within 12 months of the fracture. The most common therapies prescribed were calcitonin (56\%) followed by bisphosphonates $(35.1 \%)$. Osteoporosis medication use within the previous 12 months was the best predictor of subsequent treatment (hazard ratio $[\mathrm{HR}]=19.46$; 95\% confidence interval [CI], 16.02-23.63). A retrospective study, using a claims database, of postmenopausal women who sustained a distal radial fracture revealed that the rate of treatment for osteoporosis decreased significantly with increasing age $(\mathrm{p}<0.001)$, with $36 \%$ of patients age 55 to 59 years receiving treatment compared to $21.4 \%$ (age $75-79$ years), 25.7\% (age 80-84 years), 9.1\% (age 85-89 years), $4.2 \%$ (age 90-94 years), and 4.7\% (age $\geq 95$ years). ${ }^{18}$

The management of osteoporosis can be challenging in the older senior. Limited data regarding efficacy of drug therapy, multiple co-morbid conditions, increased risk for side effects from medications, and financial constraints have contributed to a discrepancy between the number of older seniors at risk for osteoporosis and the number being evaluated and treated. It is important for healthcare providers to be fully aware of the potential risks and benefits of diagnosing and treating osteoporosis in the older senior population.

\section{Pathophysiology of fractures}

The two main factors that impact risk for a low-trauma fracture are skeletal fragility (eg, low bone density and poor bone quality) and falls. The risk for low bone density increases with age and significantly impacts bone strength. While difficult to measure, bone quality (alterations in bone geometry and microarchitecture) is also thought to be reduced with aging and contributes to compromised structural integrity of bone. ${ }^{25}$ In the older senior, falls become a greater factor in the risk for fractures.

It is estimated that $50 \%$ of seniors 85 years of age and older will fall at least once per year and half of those who fall will do so more than once. ${ }^{26}$ Approximately 5\% of these falls result in a fracture. ${ }^{26}$ The risk for falls increases with advanced age. ${ }^{27,28}$ According to data from the National Center for Injury Prevention and Control, US seniors age 85 years of age and older had a much higher crude non-fatal and fatal fall rate compared to seniors age 65 to 69 years (nonfatal: 10.7 vs 2.5 per 100 persons and fatal: 143.7 vs 9.2 per 100,000 persons). ${ }^{29}$

The more one falls, the greater their risk for fracture. Falls and fracture risk were evaluated in a large prospective cohort study of frail elderly in residential care facilities (mean age 85.7 years). ${ }^{28}$ Fall and fracture rates of 214 and 12.1 per 100 person years, respectively, were documented over the median 705 day follow-up period. Eighty-two percent of the fractures could be attributed to a fall. Subjects who fell frequently ( $>3.08$ falls per person-year) were 3 times more likely to suffer a fracture compared to subjects who did not fall (incident risk ratio $=3.35 ; 95 \%$ CI, 2.38-4.72). Fall rate was an independent predictor of fracture risk $(\mathrm{p}<0.001)$.

The risk for falls increases with advanced age due to a variety of factors. Impaired balance, gait and mobility; and poor vision, reduced muscle strength, and impaired cognition have all been found to be strong risk factors for falls. ${ }^{26,30}$ In addition, the use of multiple medications, especially psychoactive medications such as benzodiazepines, antidepressants, and antipsychotics, and certain co-morbid disease states such as stroke, Alzheimer's dementia and Parkinson's disease, have been strongly associated with falls and fractures. ${ }^{26,30-32}$ The ability to adapt to falls also decreases with aging. Older seniors are more likely to sustain a hip fracture because they tend to fall backwards or sideways; leaving them unable to catch themselves or break their fall..$^{33,34}$

Vitamin D also plays an important role in bone strength and falls, with detrimental effects found in patients with vitamin D insufficiency and deficiency. It is estimated that $40 \%$ to $100 \%$ of US and European older men and women living in the community are insufficient or deficient in vitamin D. ${ }^{35}$ A recent study of long-term care residents (mean age 85 years) found that although $91 \%$ of patients were receiving vitamin D 
supplementation, 49.4\% were vitamin D insufficient and 16\% were found to be vitamin D deficient. ${ }^{36}$ In an older ambulatory population (mean age 78 years) where most of the patients were taking vitamin D supplements, $81 \%$ were found to be either insufficient or deficient in vitamin D. ${ }^{37}$

Reduced 25-hydroxy vitamin D (25(OH) vit. D) concentrations lead to reduced calcium absorption, secondary hyperparathyroidism, an increase in bone resorption, and consequently fractures. ${ }^{38}$ A study of 119 community dwelling women (mean age 71 years) with a history of vertebral fracture found that mean bone turnover markers were significantly elevated in the vitamin $\mathrm{D}$ insufficient patients compared to those sufficient in vitamin D. ${ }^{39}$ In addition, bone mineral density (BMD) at the hip was significantly lower in the vitamin D insufficient patients than those sufficient in vitamin $\mathrm{D}(\mathrm{p}<0.01)$. A positive correlation has also been observed elsewhere between serum $25(\mathrm{OH})$ vitamin D and BMD in older women, such that vitamin D deficiency is associated with lower femoral neck BMD. ${ }^{38}$

Vitamin D is essential to maintain muscle function and strength, especially in the weight-bearing muscles of the lower body required for balance and walking. Vitamin D and its metabolites bind to skeletal muscles, affecting muscle cell growth and metabolism. ${ }^{40,41}$ A lack of vitamin D can cause muscle weakness and falls. ${ }^{40,41}$ Muscle weakness is typically in the proximal muscle groups and is characterized by a feeling of heaviness in the legs, tiring easily, and difficulty in climbing stairs and rising from a chair. ${ }^{40}$ Multiple studies have documented that vitamin D deficiency in older seniors is associated with reduced handgrip strength, inability to climb stairs, reduced walking distance, impaired leg extension power, and less outdoor activity. ${ }^{40}$ An Australian study of nursing home and hostel patients (median age 84 years) found that residents who fell had significantly lower $25(\mathrm{OH})$ vitamin $\mathrm{D}$ concentrations than other residents $(\mathrm{p}=0.02) .{ }^{41}$

\section{Screening for osteoporosis}

The prevalence of osteoporosis is high in the older senior; however, many do not realize they have the disease. According to NHANES data from 1988 to 1994 , only $1.3 \%$ and $1.6 \%$ of men and $12.1 \%$ and $9.7 \%$ of women age 75 to 84 years and 85 years and older, respectively, reported they had osteoporosis. ${ }^{42}$ However when tested, $6.4 \%$ and $13.7 \%$ of men and $32.5 \%$ and $50.5 \%$ of women, respectively, had the disease. BMD testing using central dual-energy $\mathrm{x}$-ray absorptionmetry (DXA) is the gold standard for identifying patients with osteoporosis. BMD testing is cost-effective in the older senior who is at highest risk for osteoporosis and has been show to significantly influence the decision to initiate drug therapy..$^{20,43,44}$ In a report by the US Preventive Services Task Force, it was estimated that only 75 and 143 women between 75 and 79 years of age would need to be screened (and subsequently treated if necessary) to prevent one vertebral fracture and one hip fracture, respectively. ${ }^{45}$ This is in comparison to needing to screen 458 and 1856 women between the ages of 60 and 64 years. Universal bone density screening in women 65 years of age and older followed by treatment with alendronate was found to be more costeffective with increasing age. ${ }^{43}$ The cost per quality adjusted life year (QALY) gained was approximately US\$43,000 for 65-year-old women, US\$5600 for 75-year-old women and cost saving for women 85 or 95 years of age or older. A similar analysis of the cost-effectiveness of densitometry followed by treatment in men revealed a cost per QALY gained of $<\mathrm{US} \$ 50,000$ in all men 65 years of age or older with a prior clinical vertebral fracture and men 80 years of age or older regardless of prior fracture. ${ }^{44}$ In the United Kingdom (UK), treatment with alendronate was cost effective (threshold value of $£ 30,000$ or $€ 43,000 /$ QALY gain) in women 60 years of age or older with osteoporosis (T-score -2.5 or below) and in women 50 years or older with a previous low-trauma fracture. ${ }^{46}$ Treatment with alendronate was cost saving in women 80 years or older with a prior low-trauma fracture. While alendronate was most cost effective (due to generic availability), most other therapies for osteoporosis were found to be cost effective in women aged 70 years and older with osteoporosis.

While guidelines recommend BMD testing in all women 65 years of age and older and men 70 years of age and older regardless of clinical risk factors, many older seniors do not receive a central DXA test. ${ }^{5,20,47,48}$ In the year 2000, the US Medicare system paid for 1.75 million bone density tests, which would account for only approximately $9 \%$ of US women over the age of 65 years. ${ }^{49}$ Similar results were seen in a study of bone mass measurement claims in US Medicare beneficiaries over the age of 65 years. ${ }^{50}$ From 1999 to 2005 , only $30 \%$ of women and $4.4 \%$ of men underwent central DXA testing. According to a retrospective study of US Medicare administrative claims between 1999 and 2001, bone density screening of eligible women decreased with advancing age. ${ }^{48}$ Twenty-seven percent of eligible women between 66 and 70 years of age received bone density testing compared to only $16 \%$ of women age 81 to 85 years of age and $9.7 \%$ of women between 86 and 90 years of age. While testing rates were high in an academic geriatric practice, older seniors and those with lower functional status were less likely to be tested. ${ }^{51}$ 
Central DXA BMD testing is under-utilized in the older senior. Logistical and cost issues associated with central DXA testing in institutionalized older seniors may be one of the main reasons. Calcaneal or forearm BMD measurements using portable quantitative ultrasound or peripheral DXA devices can be an alternative to assist with risk stratification in this population. ${ }^{52-55}$ In addition, the 10-year probability for hip or major osteoporotic fracture can be calculated using selected clinical risk factors in the absence of BMD results with the World Health Organization (WHO) Fracture Risk Assessment Tool (FRAX). There are several international versions of this tool and four versions available specifically for Asians, Caucasians, Blacks, and Hispanics residing in the US. This tool is accessible at http://www.shef.ac.uk/FRAX/. ${ }^{56}$

For the community-dwelling older senior, it is possible that the under-utilization of BMD testing is due to the misconception that it is too late to make an impact on osteoporosis in this population. It is important for healthcare providers to realize osteoporosis risk and adverse outcomes from fractures increase with age and that evidence consistently shows that those at highest risk for fracture are the ones that benefit most from interventions such as pharmacological therapy. ${ }^{57}$

\section{Diagnosis of osteoporosis}

The diagnosis of osteoporosis is based on a low BMD T-score at the lumbar spine, total hip or femoral neck. ${ }^{5} \mathrm{~A}$ BMD T-score of -1.0 or higher (ie, a BMD within 1 standard deviation of that expected for a young, healthy adult of the same sex) is considered normal. A T-score between -1.0 and -2.5 is considered osteopenia, and a T-score of -2.5 or lower (ie, 2.5 or more standard deviations below the expected BMD) is considered osteoporosis. Patients with a T-score of -2.5 or lower and evidence of low-trauma fractures have severe osteoporosis. A diagnosis of osteoporosis may also be made clinically in at-risk individuals based on the presence of a low-trauma fracture. ${ }^{5}$

\section{Evaluation of the older senior with osteoporosis}

All older seniors should undergo an investigation for secondary causes for osteoporosis as a part of the full evaluation of osteoporosis. Routine laboratory testing recommended for identifying the most common secondary causes for osteoporosis in older seniors is summarized in Table 1. Vitamin D status is important to assess on a yearly basis in the older senior. There is, however, no universal agreement on what $25(\mathrm{OH})$ vitamin D concentrations constitute deficiency or insufficiency. Currently, most experts in the US agree that concentrations $\geq 75 \mathrm{nmol} / \mathrm{L}(\geq 30 \mathrm{ng} / \mathrm{mL}$ ) define vitamin $\mathrm{D}$ sufficiency, concentrations between 50 and $72.5 \mathrm{nmol} / \mathrm{L}(20-29 \mathrm{ng} / \mathrm{mL})$ define vitamin D insufficiency, and concentrations $<50 \mathrm{nmol} / \mathrm{L}(<20 \mathrm{ng} / \mathrm{ml})$ defines vitamin D deficiency. ${ }^{35}$

All older seniors should be asked annually about the occurrence of falls, as patients who fall are at an increased risk for future falls. Any patient that reports a single fall should undergo a basic evaluation of gait/balance (eg, "Get Up and Go Test"). ${ }^{58}$ Two or more falls or one fall with injury within the past year should prompt a thorough fall risk assessment. ${ }^{59}$ Items that should be included as part of a fall risk assessment are summarized in Table 2..$^{58-60}$

\section{Treatment}

\section{Bone-healthy lifestyle}

Exercise, fall prevention and smoking cessation in the older senior with osteoporosis should be encouraged whenever

Table I Suggested routine laboratory tests for the evaluation of secondary causes of osteoporosis in the older senior

\begin{tabular}{ll}
\hline Laboratory test & Secondary cause \\
\hline Serum creatinine and blood urea nitrogen & Chronic kidney disease \\
Serum alkaline phosphatase & Paget's disease; osteomalacia \\
Serum thyroid-stimulating hormone concentration & Hyperthyroidism or over-supplementation of thyroxine \\
Serum calcium and phosphorous concentrations & Vitamin D deficiency; malabsorption \\
24 -hour urinary calcium & Excessive urinary excretion of calcium \\
Total serum testosterone (men) & Hypogonadism \\
25 -hydroxy vitamin D & Vitamin D insufficiency/deficiency \\
Intact serum parathyroid hormone & Primary or secondary hyperparathyroidism \\
Serum protein electrophoresis & Multiple myeloma \\
Complete blood count & Leukemia \\
Liver function tests & Chronic liver disease \\
\hline
\end{tabular}


Table 2 Fall risk assessment in the older senior ${ }^{58-60}$

\section{Fall risk assessment ${ }^{a}$}

Basic fall history (eg, number and circumstances surrounding falls)

Medication review: eliminate unnecessary or inappropriate psychoactive medications including antipsychotics, anxiolytics, hypnotics, antidepressants, muscle relaxants, anticholinergics and narcotics, and medications such as diuretics or certain antihypertensives known to cause postural hypotension

Document alcohol consumption

Document acute or chronic medical conditions

Document orthostatic vitals (blood pressure and pulse)

Visual acuity testing

Basic gait, balance, and strength evaluation (eg, basic neurological exam to evaluate muscle strength, cerebellar function and peripheral sensory function; "Get Up and Go Test" )

Cognitive status (eg, Mini-Mental State Exam)

Evaluation of home and personal safety

aRecommended assessment for patients with two or more falls or one fall with injury within the past year.

b"Get Up and Go Test": patients are instructed to stand from a seated position without using their hands, walk 10 feet, turn around, return to the chair and sit down. Patients that take longer than 30 seconds are at a higher risk for falls.

possible to help preserve BMD and reduce fracture risk (Table 3). ${ }^{58-66}$ Data show that aerobic, weight bearing and resistance exercise increases BMD of the spine and that walking alone increases BMD of both the hip and the spine in postmenopausal women. ${ }^{62}$ This type of exercise should be encouraged in older seniors too. However, a medical examination is recommended to make sure the patient is safe to exercise and to assess muscle strength, range of motion, level of physical activity, fitness, gait and identify balance problems. ${ }^{61}$ Exercise regimens should be tailored to individual patient abilities. Loading exercises that can be beneficial to the hip can result in compression fractures

Table 3 Recommendations for a bone-healthy lifestyle in the older senior

\begin{tabular}{|c|c|c|}
\hline Intervention & Recommendations & Comments \\
\hline Exercise $^{61-63}$ & $\begin{array}{l}\text { - Moderate-intensity aerobic physical activity } \\
\text { for } \geq 30 \text { minutes for } 5 \text { days/week. } \\
\text { - } 8 \text { - } 10 \text { exercises using the major muscle } \\
\text { groups for } \geq 2 \text { days/week } \\
\text { - } \geq 10 \text { minutes of activities to maintain or } \\
\text { increase flexibility for } \geq 2 \text { days/week } \\
\text { - Exercises to maintain/improve balance } \\
\text { in older seniors with substantial fall risk }\end{array}$ & $\begin{array}{l}\text { A physical examination should be } \\
\text { performed prior to starting an exercise } \\
\text { regimen. The exercise regimen should } \\
\text { be tailored to each individual patient. }\end{array}$ \\
\hline Fall prevention ${ }^{58-60,64-66}$ & $\begin{array}{l}\text { - Physical activity (as above) } \\
\text { - Home environment modifications } \\
\text { - Vision assessment } \\
\text { - Use of ambulation-assistive devices } \\
\text { - Treatment of cardiovascular causes of falls } \\
\text { - Eliminating unnecessary medications } \\
\text { - Vitamin D supplementation }\end{array}$ & \\
\hline Calcium $^{5,71,72}$ & $\begin{array}{l}\text { - } 1200-1500 \mathrm{mg} \text { calcium divided two } \\
\text { to three times daily }\end{array}$ & $\begin{array}{l}\text { Older seniors taking proton pump } \\
\text { inhibitors may benefit from calcium } \\
\text { citrate. Patients should be counseled } \\
\text { regarding possible side effect of } \\
\text { constipation. }\end{array}$ \\
\hline Vitamin $D^{5,35}$ & $\begin{array}{l}\text { To avoid deficiency } \\
\text { - } 800-1000 \text { IU vitamin D3 daily OR } \\
\text { - 50,000 IU vitamin D2 every 2-4 weeks } \\
\text { To treat deficiency } \\
\text { - 50,000 IU vitamin D2 every week for } \\
\text { 8-I6 weeks }\end{array}$ & \\
\hline
\end{tabular}

Abbreviation: IU, international units. 
of the spine, so the intensity/resistance of exercise might need to be adjusted to BMD. ${ }^{61}$ An example daily exercise regimen recommended for seniors is: 1) a 5- to 10 -minute warm-up session of walking, stretching, or calisthenics; 2) a 15 - to 20-minute muscle conditioning program (eg, weight training); 3) 15 to 20 minutes of aerobics (eg, fast walking, jogging, stair stepping, biking, or vigorous dancing); and 4) a 5- to 10-minute cool-down session (eg, walking or stretching) ${ }^{61}$ Recently published guidelines from the American Heart Association recommend that all seniors (65 years and older) need moderate-intensity aerobic physical activity for at least 30 minutes on 5 days of each week, or vigorous-intensity aerobic activity for at least 20 minutes on 3 days of each week. ${ }^{63}$ The guideline also includes recommendations for 8 to 10 exercises using the major muscle groups on 2 or more days per week, at least 10 minutes of activities to maintain or increase flexibility on at least 2 days of each week, and exercises to maintain or improve balance in those with substantial risk of falls. ${ }^{63}$ Although not necessarily targeted for the "older senior," these recommendations come from data that regular physical activity reduces risk of many diseases, plays a therapeutic role in diseases such as osteoporosis, reduces risk of falls and injuries from falls, and reduces functional limitations. Thus, exercise and muscle strengthening should still be encouraged as much as possible in the older senior.

Other methods of preventing falls include home environment modifications (eg, removing loose rugs or extension cords, repairing rickety stairs, adding grab bars in the bathroom, increasing lighting), assessing vision and treating any remedial visual abnormalities, assessing need for ambulation-assistive devices (eg, canes and walkers), treatment of cardiovascular causes of falls (eg, orthostatic hypotension, arrhythmias) and eliminating medications that can increase risk of falls (eg, antipsychotic agents, benzodiazepines, antidepressants, antihypertensives, diuretics). ${ }^{58}$

Smoking cessation is also recommended for the older senior with osteoporosis. One year of smoking cessation has been shown to significantly increase BMD in the femoral trochanter $(p=0.02)$ and total hip $(p=0.03)$ relative to continuation of smoking in postmenopausal women. ${ }^{67}$ Moreover, smoking cessation has been found to reduce the risk of hip fracture compared to continuation of smoking in non-elderly women, although the benefit was not evident until 10 years after cessation. ${ }^{68}$ Despite a lack of data in older seniors and that the benefits of smoking cessation for osteoporosis may be delayed, the other health benefits of smoking cessation (eg, vascular, pulmonary) make it important for all older seniors.

\section{Hip protectors}

External hip protectors are specialized undergarments designed to pad the area surrounding the hip decreasing the force of impact from a sideways fall. Individual studies evaluating the effectiveness of these products have demonstrated conflicting results. ${ }^{69}$ Poor compliance is the main drawback with these devices, as patients tend to find them uncomfortable and cosmetically unappealing. A recent metaanalysis of randomized controlled trials demonstrated no benefit from hip protectors in community-dwelling seniors. ${ }^{69}$ In addition, there was no difference in hip fracture rates in a large, multicenter, randomized controlled trial of nursing home residents. ${ }^{70}$ These data indicate that hip protectors are ineffective and should not be recommended alone for the prevention of hip fractures.

\section{Calcium and vitamin D}

All patients with osteoporosis, regardless of age, should receive adequate calcium and vitamin $\mathrm{D}$ (Table 3).,55,71,72 Diet alone is usually not adequate to maintain recommended intakes of calcium and vitamin $\mathrm{D}$, and supplementation is almost always necessary. Many studies have evaluated the effects of calcium and vitamin D on BMD and fractures and vitamin D on falls in older adults. A meta-analysis of calcium and calcium/vitamin D supplementation found that the supplements significantly reduced fracture risk by $12 \%$ $(\mathrm{p}=0.004)$ and reduced bone loss by $0.54 \%(\mathrm{p}<0.0001)$ at the hip and $1.19 \%(\mathrm{p}<0.0001)$ in the spine. ${ }^{73}$ In a subgroup analysis based on age, fracture risk reduction was significantly greater in those aged 70 to 79 years (relative risk [RR] $0.89,95 \%$ CI $0.82-0.96$ ) and those aged $\geq 80$ years (RR 0.76 , 95\% CI $0.67-0.87)$ compared to those age 50 to 69 years (RR 0.97, 95\% CI 0.92-1.02), $\mathrm{p}=0.003 .{ }^{73}$ In the same metaanalysis, calcium doses of $\geq 1200 \mathrm{mg}$ per day and vitamin D doses of $\geq 800$ international units (IU) per day were found to be statistically better at preventing fractures than lower doses $\left(p=0.006\right.$ and $p=0.03$, respectively). ${ }^{73}$

Vitamin D monotherapy in doses between 700 to $800 \mathrm{IU}$ per day has also been shown in a meta-analysis to reduce the risk of hip and any non-vertebral fractures in ambulatory and institutionalized seniors. ${ }^{74} \mathrm{~A}$ Cochrane review published around the same time found that vitamin $\mathrm{D}$ alone showed no statistically significant effect on hip, vertebral or any new fracture. ${ }^{75}$ However, it does not appear that the authors evaluated the data based on the dose of vitamin D. An even more recent meta-analysis concluded that oral vitamin D appears to reduce the risk of hip fractures only when it is combined with calcium supplementation. ${ }^{76}$ Studies regarding the use of 
vitamin D supplements to prevent fractures are conflicting, likely because patient populations may have different baseline $25(\mathrm{OH})$ vitamin D concentrations, interventions may utilize different forms of vitamin $\mathrm{D}$ (eg, ergocalciferol vs cholecalciferol), and doses may be different (eg, $<800$ IU per day vs $\geq 800$ IU per day). Unfortunately, none of the studies described above performed analyses to evaluate effects based on subject age.

The effects of vitamin D monotherapy on falls was evaluated in a meta-analysis that found that vitamin $\mathrm{D}$ reduced the odds ratio of falling by $22 \%$ (corrected odds ratio $0.78,95 \%$ CI 0.64-0.092) compared with patients (mean age ranged from 70 to 85 years) receiving calcium or placebo. ${ }^{64}$ Since the meta-analysis of vitamin D and falls was published, multiple other studies evaluating effects of vitamin D supplementation on falls have been published, most of which are positive. ${ }^{65}$ A prospective, randomized, multi-dose study of nursing home residents (mean age 89 years) found that those taking 800 IU per day of vitamin D2 supplementation had a $72 \%$ lower adjusted-incidence rate of falls than those taking placebo (RR $0.28,95 \%$ CI $0.11-0.75$ ) over 5 months. ${ }^{77}$ Patients taking $200 \mathrm{IU}$ per day, $400 \mathrm{IU}$ per day and $600 \mathrm{IU}$ per day of vitamin $\mathrm{D}$ had similar fall rates to those taking placebo. A 2005 study of 625 independent and institutionalized older seniors (mean age 83 years) found that ergocalciferol $(10,000$ IU weekly then 1000 IU daily) and calcium carbonate $600 \mathrm{mg}$ daily demonstrated an incident rate ratio of falling of 0.73 (95\% CI $0.57-0.95)$ compared to placebo. ${ }^{66}$ This translates to 8 patients treated with vitamin D over 1 year to prevent one fall from occurring. ${ }^{66}$ Two negative studies in older seniors (mean ages 85 and 84 years, respectively) utilized bolus dosing of ergocalciferol 100,000 units (every 3 months and every 4 months, respectively), which may explain their finding of lack of efficacy to prevent falls and fractures. ${ }^{78,79}$ Evidence suggests that large infrequent doses of ergocalciferol may provide only short-term benefits, as compared to cholecalciferol. ${ }^{65}$

Although data regarding vitamin D monotherapy might be conflicting regarding fracture and fall reduction, it is apparent that combination calcium and vitamin D supplementation is beneficial for older seniors. In addition, supplementation is inexpensive and well-tolerated. Vitamin D3 (cholecalciferol) is the preferred formulation for vitamin D supplementation. The total daily vitamin $\mathrm{D}$ dose can be given via a multivitamin, calcium plus vitamin $\mathrm{D}$, and/or vitamin $\mathrm{D}$ alone. Often a combination of the products containing vitamin D is necessary to achieve adequate $25(\mathrm{OH})$ vitamin $\mathrm{D}$ concentrations.
Calcium is typically supplemented utilizing either calcium carbonate or calcium citrate. The calcium citrate form may be advantageous for older seniors, since calcium citrate absorption does not rely on gastric acid like calcium carbonate, and older seniors may suffer from achlorhydria. Moreover, patients taking proton pump inhibitors (PPIs) may benefit more from supplementation with calcium citrate. One small study found that calcium carbonate absorption was inhibited by co-administration with omeprazole. ${ }^{71}$ Since many older seniors may also take a PPI, it may be prudent to recommend supplementation with calcium citrate in those patients. In addition, it may be appropriate to assess the need of the PPI, as long-term treatment with PPIs has been associated with increased risk of hip fracture. ${ }^{72}$ It is not known if the increased risk of hip fracture is due to the effect of PPIs on calcium absorption.

Calcium and vitamin D supplementation in the older senior is well tolerated, other than possible constipation associated with the calcium component. Hypercalcemia and hyperphosphatemia rarely occur. Vitamin D toxicity is extremely rare and usually only occurs with long-term administration of extremely high doses, such as 50,000 IU per day or more. ${ }^{35}$ Currently, the tolerable upper intake level of vitamin D is set at 2000 units per day, although with proper monitoring older seniors may benefit from higher doses. Doses of vitamin D should be titrated to achieve a serum $25(\mathrm{OH})$ vitamin $\mathrm{D}$ concentration of 75 to $150 \mathrm{nmol} / \mathrm{L}$ (30-60 $\mathrm{ng} / \mathrm{mL}$ ) to fully maximize calcium absorption and benefits on BMD and muscles. ${ }^{35}$

\section{Drug therapy}

The 2008 National Osteoporosis Foundation (NOF) Clinician's Guide recommends treatment of postmenopausal women and men 50 years of age or older with (1) a hip or vertebral fracture, (2) a femoral neck, total hip, or spine T-score of -2.5 or less measured by central DXA, or (3) a T-score between -1.0 and -2.5 measured by central DXA (ie, osteopenia) and other prior fractures, a secondary cause associated with a high risk of fractures, a 10-year hip fracture probability of $3 \%$ or higher, or a 10 -year probability of major osteoporosis-related fracture (vertebral, hip, forearm, or humerus fracture) of $20 \%$ or higher. ${ }^{5}$ These probabilities are calculated using the WHO FRAX tool. ${ }^{56}$ According to this guideline all older seniors with the diagnosis of osteoporosis would warrant drug therapy. In addition, using the US FRAX to calculate the 10-year probability for fracture, the majority of Caucasian women 80 years of age or older would meet criteria for treatment at 
a T-score of -1.7 or less even in the absence of additional clinical risk factors.

The NOF Clinicians Guide is more aggressive in recommending drug therapy in the older senior compared to other Guidelines. The National Osteoporosis Guideline Group from the UK published in 2008 recommendations for the prevention and treatment of osteoporosis in postmenopausal women and men age $\geq 50$ years. ${ }^{80}$ They recommend agebased treatment thresholds using the 10 -year probability of a major osteoporotic fracture from the UK specific FRAX tool. According to this guideline, the intervention threshold for an 80 -year-old man with or without previous fracture and an 80-year-old postmenopausal woman with no previous fracture would be a 10-year probability of major osteoporotic fracture of at least 30\%. An updated list of National and Regional Osteoporosis Guidelines can be found at the International Osteoporosis website: http://www.iofbonehealth. org/health-professionals/national-regional-guidelines/ evidence-based-guidelines.html.

Drug therapy for the management of osteoporosis in the older senior is summarized in Table $4 .{ }^{81-105}$ The majority of pharmacological interventions available are considered antiresorptive (bisphosphonates, calcitonin, raloxifene, and hormone replacement therapy). Only parathyroid hormone is considered truly anabolic or bone building. The mechanism of action of strontium ranelate is not completely understood, but is thought to reduce bone resorption while maintaining bone formation. All these interventions have been shown to reduce the risk of vertebral fracture when given with calcium and vitamin D supplements. Some have been shown to also reduce the risk of non-vertebral fractures and specifically hip fractures. ${ }^{81,88,89,93,99}$ Intravenous zoledronic acid may reduce mortality in patients with a previous hip fracture. ${ }^{92}$

When deciding whether or not to institute drug therapy for the management of osteoporosis in the older senior, several factors need to be taken into consideration. First it is important to determine if there is evidence to support a benefit from osteoporosis therapy in the older senior. In 2003, the average additional life span for a 75-year-old in the US was 11.8 years and for an 85 -year-old was 6.8 years. ${ }^{106}$ Data for most osteoporosis therapies show significant decreases in vertebral fracture rates as early as 6 months to 1 year..$^{93,107,108}$ Unless there is a comorbid condition that is expected to significantly reduce life expectancy, many older seniors will live long enough to potentially derive a benefit from osteoporosis drug therapy.

Similar to other disease states, efficacy data are lacking in the older senior population, with the majority of information coming from post hoc subgroup analyses. In an analysis of data from the Fracture Intervention Trial with alendronate, the relative risk reductions for clinical fractures at the hip, spine and wrist with alendronate therapy were found to be constant across all age groups up to the age of 85 years. ${ }^{109}$ The absolute risk reduction (ARR) between alendronate and placebo increased with increasing age. For example, the ARR for hip fracture was 11 per 10,000 person-years for women 55 to 64 years of age and 53 per 10,000 person-years for women 75 to 85 years of age. Comparable results were seen in a post hoc analysis by Ensrud and colleagues. ${ }^{57}$ Statistically significant relative risk reductions in new vertebral fractures were seen with alendronate therapy compared to placebo both in women $<75$ years of age (relative risk $[R R]=0.49$; $95 \% \mathrm{CI}, 0.35-0.68)$ and 75 to 82 years of age $(\mathrm{RR}=0.62$; 95\% CI, 0.41-0.94).

Pivotal studies of risedronate compared to placebo did not exclude subjects based on age. A pooled analysis of data from these studies demonstrated a statistically significant $44 \%$ relative risk reduction for new vertebral fractures at 3 years with risedronate therapy in women between 80 and 100 years of age $(\mathrm{HR}=0.56,95 \% \mathrm{CI}=0.39-0.81, \mathrm{p}=0.03) .{ }^{110}$ There was no significant difference in non-vertebral fracture risk between risedronate and placebo in the population. Risedronate is the only oral therapy to be evaluated in a large, prospective clinical trial with hip fracture reduction as the primary endpoint. ${ }^{88}$ Postmenopausal women were enrolled into two arms. The osteoporosis arm included women aged 70 to 79 years with documented osteoporosis. The risk factor arm included women 80 years and older (mean age 83 years) with either one non-skeletal risk factor for hip fracture or osteoporosis. The majority of the subjects in this arm did not have central DXA results and were enrolled based on risk factors for fall. Overall, risedronate reduced the risk of hip fractures by $30 \%(\mathrm{RR}=0.70,95 \% \mathrm{CI}, 0.6-0.69)$. However, when the two groups were evaluated independently, the incidence of hip fracture was not significantly reduced in the risk factor $\operatorname{arm}(\mathrm{RR}=0.8,95 \% \mathrm{CI}, 0.6-1.2)$.

The HORIZON-Pivotal Fracture Trial (PFT) compared zoledronic acid infused intravenously once-yearly to placebo on vertebral and hip fracture risk in postmenopausal women with osteoporosis. ${ }^{93}$ A post hoc analysis of results stratified according to age groups ( $<70$ years, $70-74$ years and $\geq 75$ years) demonstrated that new vertebral and nonvertebral fractures were significantly reduced in all age groups. ${ }^{111}$ In this analysis, the relative risk for new vertebral fractures were reduced by $60 \%(\mathrm{p}<0.001)$ in those women $\geq 75$ years of age compared to $80 \%$ ( $p<0.001)$ 
in those $<70$ years of age. Hip fracture risk was only significantly reduced in the $<70$ years age group $(R R=0.30$; $\mathrm{p}<0.05)$. The HORIZON-Recurrent Fracture Trial (RFT) randomized men and women with a prior hip fracture to receive once yearly intravenous infusions of zoledronic acid. ${ }^{92}$ Over $50 \%$ of the subjects enrolled were 75 years of age or older. A statistically significant $35 \%$ reduction in any clinical fracture $(\mathrm{p}=0.001)$ and $28 \%$ reduction in all cause mortality $(p=0.01)$ was demonstrated in the treatment group compared to placebo. The reduction in hip fracture risk did not reach statistical significance.

An analysis of the Fracture Prevention Trial with teriparatide demonstrated a similar benefit with therapy compared to placebo in younger and older women. ${ }^{112,113}$ For women younger than 75 years and those aged 75 years and older, teriparatide therapy resulted in an ARR for new vertebral fracture of $9.2 \%(R R=0.35, p<0.01)$ and $9.9 \%(R R=0.35$, $\mathrm{p}<0.05)$, respectively compared to placebo. ${ }^{112}$ Non-vertebral fracture risk was not significantly reduced in the $\geq 75$ years of age group with teriparatide therapy $(R R=0.75, p=0.66)$. However, the treatment-by-age interaction $(p=0.42)$ indicated that the effect of teriparatide on non-vertebral fractures was not significantly different between those $<75$ or those $\geq 75$ years of age.

A pre-planned pooled analysis of studies with oral strontium ranelate compared to placebo evaluated efficacy in women with osteoporosis who were between the age of 80 and 100 years (mean age 84 years). ${ }^{114}$ Over 3 years, the relative risk for vertebral and non-vertebral fractures was significantly reduced by $32 \%(p=0.013)$ and $31 \%(p<0.011)$, respectively in the strontium-treated patients. Hip fracture risk reduction did not reach statistical significance $(32 \%$, $\mathrm{p}=0.112$ ).

The Multiple Outcomes of Raloxifene Evaluation (MORE) study enrolled postmenopausal women age 31 to 80 years. ${ }^{94}$ The mean age of the study subjects was 67 years. Subgroup analyses based on age are not available.

The Women's Health Initiative evaluated the effects of estrogen with or without progestin on several chronic disease states including fractures in healthy postmenopausal women age 50 to 79 years. ${ }^{104,105}$ Reductions in clinical vertebral and hip fractures were seen, and the results did not differ with age stratification. Hormone replacement therapy is only indicated in the US for the prevention of osteoporosis and should not be used solely for this purpose. ${ }^{5}$

Subgroup analyses, while not ideal, have consistently demonstrated a significant reduction in vertebral fracture risk with drug therapy across all age groups. The inconsistent benefit seen in non-vertebral fracture risk in older patients may be due to the fact that improvement in bone strength is overshadowed by increasing fall risk in this population.

Only one study has been prospectively designed to evaluate the efficacy of therapy in the older patient (mean age 78.5 years; range 65-91 years) residing in a long-term care facility. In this study, alendronate $10 \mathrm{mg}$ po once daily for 2 years significantly increased BMD at the hip and spine compared to placebo, with no difference in adverse events between groups. ${ }^{115}$ Fracture risk was not evaluated in this study.

Intranasal calcitonin is frequently prescribed in the older senior population, possibly due to its benign side effect profile and ease of administration. ${ }^{22}$ Calcitonin has not been shown to improve hip BMD or reduce hip fracture risk. ${ }^{97}$ Based on vertebral fracture efficacy, it is considered a third line therapy option for osteoporosis management. Efficacy data are not available for the older senior; however in the Prevent Recurrence of Osteoporotic Fractures study, 21\% to 25\% of the women enrolled were $\geq 75$ years of age. ${ }^{97}$

Some evidence suggests that calcitonin may have an analgesic effect. Small studies have demonstrated a short-term benefit from calcitonin therapy on pain in senior men and women who have suffered an acute vertebral compression fracture. ${ }^{98,116,117}$ The short-term ( $\sim 4$ weeks) administration of intranasal calcitonin for pain relief should not preclude the use of more efficacious therapies, such as bisphosphonates, for the treatment of osteoporosis.

Limited studies have evaluated the benefit of pharmacologic treatment in men. ${ }^{118-123}$ The mean age of the subjects in the majority of the studies was $<65$ years. ${ }^{118,121-123}$ While small in size, these studies did demonstrate improvements in BMD similar to studies in postmenopausal women and two studies showed significant reductions in vertebral fracture risk. ${ }^{121,123}$ Two studies have evaluated the effect of risedronate on hip fracture risk in older men. In 280 men post stroke (mean age 76 years), $2.5 \mathrm{mg}$ risedronate daily significantly reduced hip fracture risk by $81 \%(\mathrm{RR}=0.19,95 \% \mathrm{CI}, 0.04-0.89) \mathrm{com}-$ pared to placebo. ${ }^{119}$ In 223 men with Parkinson's Disease (mean age $=71.3$ years; range 65 to 85 ), $2.5 \mathrm{mg}$ risedronate daily did not significantly reduce hip fracture risk compared to placebo $(\mathrm{RR}=0.33 ; 95 \% \mathrm{CI}, 0.09-1.20) .{ }^{120}$ More studies are needed to fully understand the benefits and risks of osteoporosis therapy in older men.

In addition to efficacy, one needs to consider the risks of pharmacological treatment in the older senior. Administration of oral bisphosphonates, which are considered first line therapy for osteoporosis, can be challenging in 


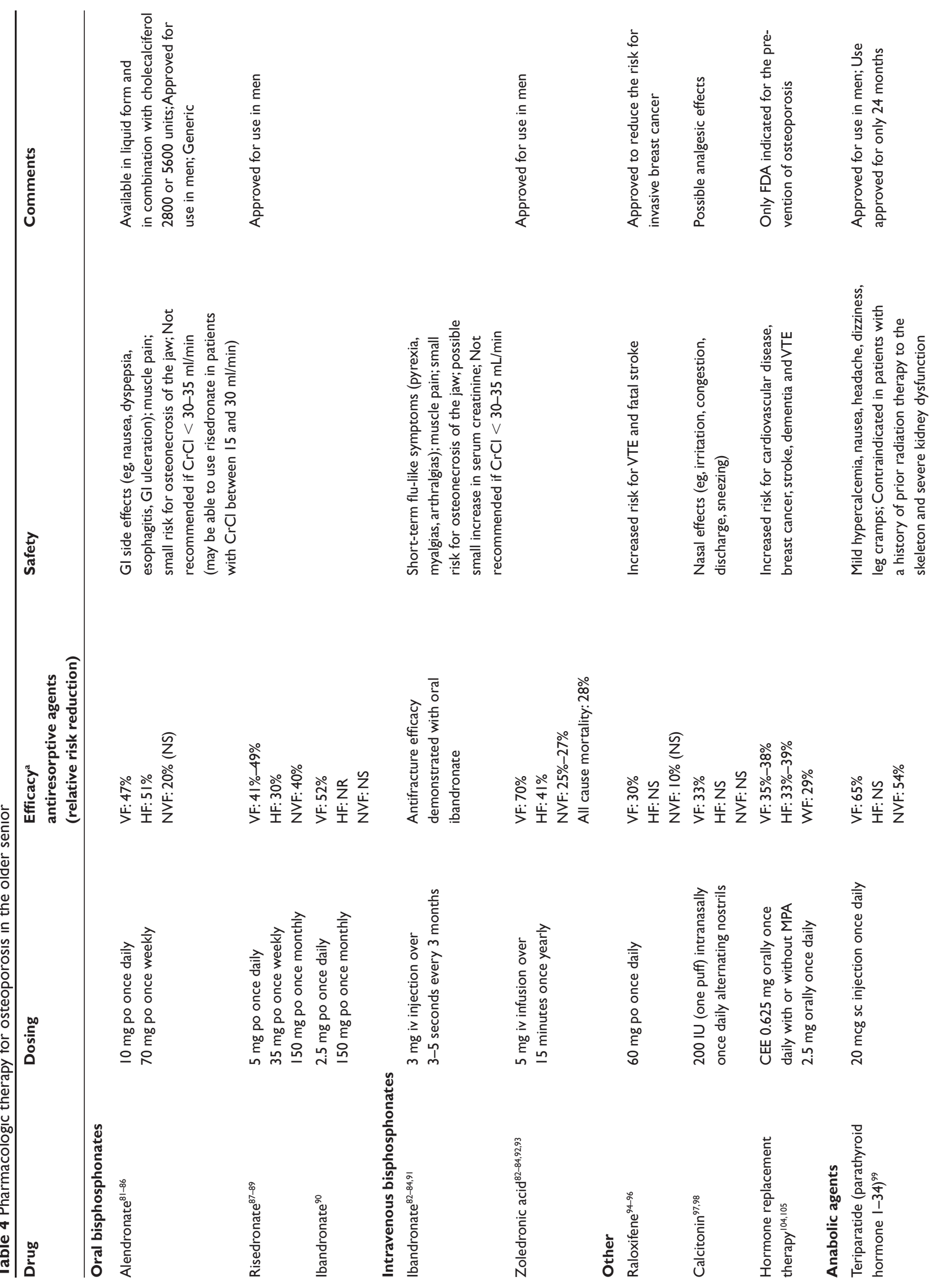


the older senior. To ensure adequate absorption, patients cannot eat, drink (other than plain water), or consume any medications for 30 to 60 minutes after taking a bisphosphonate. To reduce the risk for esophageal side effects, patients need to take the medication with at least 180 to $240 \mathrm{~mL}$ (6-8 ounces) of plain water and be able to sit upright for at least 30 to 60 minutes after taking. These instructions can be especially difficult for institutionalized or cognitively impaired seniors. A significant number of seniors have gastrointestinal complaints, which are the most common side effects of oral bisphosphonates. While clinical trial data do not indicate an increased risk for side effect in older subjects compared to younger subjects, real-world experience indicates an increased risk of these effects if the medication is not taken appropriately. ${ }^{10,124}$ A recent letter to the editor summarizes US Food and Drug Administration (FDA) reports of esophageal cancer diagnoses in patient taking oral bisphosphonates. ${ }^{125}$ It is possible that inappropriate administration contributed to some of these cases. The older senior is frequently on multiple oral medications. The addition of an oral osteoporosis medication (including calcium and vitamin D) can add complexity to an already challenging medication regimen leading to potential adherence problems. Adherence at one year is poor with these agents and studies have demonstrated a reduced fracture benefit in patients with poor adherence. ${ }^{126-128}$

Intravenous bisphosphonates are an option in the older senior who cannot tolerate or may have difficulty adhering to oral bisphosphonate therapy. Quarterly intravenous injections of ibandronate or a once yearly infusion of zoledronic acid may significantly improve adherence in this population. The most common side effects are short-term flu-like symptoms (eg, myalgias, arthralgias, pyrexia). ${ }^{91-93}$ In the HORIZON-PFT, an increased incidence of serious atrial fibrillation was observed in the zoledronic acid group (1.3\%) compared to placebo $(0.5 \%), \mathrm{p}<0.001 .^{92,93}$ No plausible biological explanation could be found. In addition, the rates of atrial fibrillation were similar between the zoledronic acid and placebo groups in the HORIZON-RFT. ${ }^{92}$ The risk for atrial fibrillation increases with age. A possible increased risk for atrial fibrillation with bisphosphonates therapy could be a concern in the older senior. Due to conflicting evidence on the link between atrial fibrillation and the use of bisphosphonates, ${ }^{129-131}$ the FDA conducted a review of all safety data and concluded that there was "no clear association between overall bisphosphonate exposure and the rate of serious or non-serious atrial fibrillation. Increasing dose or duration of bisphosphonate therapy was also not associated with an 
increased rate of atrial fibrillation." The FDA is continuing to monitor postmarket reports of atrial fibrillation in patients who have taken bisphosphonates.

Raloxifene, an estrogen agonist-antagonist, is considered a second line option for the management of osteoporosis in older seniors and is FDA-approved in the US for use in postmenopausal women at high risk for invasive breast cancer. ${ }^{132}$ It is administered orally on a daily basis, which may result in lower adherence compared with less frequently administered bisphosphonates. Side effects are also a concern with this therapy as raloxifene has been shown to increase venous thromboembolism risk by 3 -fold and fatal stroke risk $(1.2 \%$ raloxifene vs $0.8 \%$ placebo, $\mathrm{p}=0.0499) .{ }^{95,96}$

Teriparatide and parathyroid hormone 1-84 are administered by subcutaneous injection once daily. They are an option for patients that are at high risk for fracture or who cannot tolerate or fail other therapies. While side effects are limited (first dose dizziness and transient hypercalcemia), daily administration of these therapies in the older senior can be challenging.

\section{Special considerations}

Kidney function or glomerular filtration rate (GFR) declines with aging. Many older seniors with osteoporosis have estimated GFRs of $<60 \mathrm{~mL} / \mathrm{min}$ and some $<30 \mathrm{~mL} / \mathrm{min}$ without any evidence for kidney damage. ${ }^{133,134}$ According to package labeling, oral and iv bisphosphonates are not recommended for patients with a creatinine clearance $(\mathrm{CrCl})<30$ or $35 \mathrm{~mL} / \mathrm{min}$. Approximately $50 \%$ of the absorbed dose of a bisphosphonate is excreted unchanged by the kidney; therefore, reductions in kidney function have the potential to result in accumulation of the bisphosphonate. It is important to know if bisphosphonates are efficacious and safe to use in the older senior with reduced kidney function.

The influence of baseline kidney function on the safety and efficacy of once daily risedronate was evaluated in a retrospective analysis of data from 9 randomized, doubleblind, placebo-controlled trials. ${ }^{135} \mathrm{CrCl}$ was estimated using the Cockcroft and Gault method. There was no difference in side effect rates or the risk for vertebral fractures among patients with mild ( $\mathrm{CrCl} 50-79 \mathrm{~mL} / \mathrm{min})$, moderate ( $\mathrm{CrCl} 30-49 \mathrm{~mL} / \mathrm{min}$ ) or severe kidney impairment ( $\mathrm{CrCl} \mathrm{15-30} \mathrm{mL} / \mathrm{min})$. The mean age of the patients in the severe kidney impairment group was 83 years compared to 71 years in the mild group.

In a study using data with teriparatide, postmenopausal women with impaired kidney function $(\mathrm{CrCl} 30-79 \mathrm{~mL} / \mathrm{min})$ had comparable rates of adverse events, increases in BMD, and decreases in vertebral and non-vertebral fracture risk as postmenopausal women with normal kidney function $(\mathrm{CrCl} \geq 80 \mathrm{~mL} / \mathrm{min}) .{ }^{136}$ Alendronate also demonstrated similar efficacy in postmenopaual women with reduced kidney function $(\mathrm{CrCl}<45 \mathrm{~mL} / \mathrm{min})$ as women without reduced kidney function. ${ }^{137}$

The efficacy and safety of raloxifene by degree of kidney impairment was examined using data from the MORE trial. ${ }^{138}$ This post hoc analysis demonstrated raloxifene was effective and well tolerated in patients with mild to moderate kidney impairment (mean $\mathrm{CrCl} 40 \mathrm{~mL} / \mathrm{min}$ ). Package labeling indicates raloxifene should be used with caution in patients with moderate or severe renal impairment since safety and efficacy have not been established. Based on the results of these studies, teriparatide may be an option for older seniors with moderate kidney impairment (CrCl 30-49 mL/min) and oral bisphosphonates, specifically risedronate, in older seniors with severe age-related kidney impairment ( $\mathrm{CrCl}$ as low as $15 \mathrm{~mL} / \mathrm{min})$. There are no data regarding safety and efficacy of intravenous bisphosphonates in patients with severe kidney impairment, but those with a $\mathrm{CrCl} \geq 30 \mathrm{~mL} / \mathrm{min}$ were included in the HORIZON studies. Renal safety of zoledronic acid was evaluated in the HORIZON studies. A significant increase in serum creatinine of more than $0.5 \mathrm{mg} / \mathrm{dL}$ occurred at 9 to 11 days after infusion in $1.2 \%$ of the treatment group compared to $0.4 \%$ of the placebo group ( $p<0.001$ ) in HORIZONPFT. ${ }^{93}$ There was no difference between groups in serum creatinine or $\mathrm{CrCl}$ at the end of the study. In addition, no significant increase in serum creatinine was noted in the HORIZON-RFT. ${ }^{92}$

\section{Conclusion}

The older senior is at high risk for osteoporosis. Bone mineral density testing with central DXA is essential and costeffective in this population. Based on subgroup analyses of large osteoporosis trials in postmenopausal women, current osteoporosis therapies appear safe and efficacious in the older senior and most will live long enough to derive a benefit from these therapies. The risk for vitamin D insufficiency and deficiency is high and should be treated appropriately. It is important to remember that falls play a very important role in the risk for osteoporosis fractures, especially in the older senior. Strategies to reduce fall risk in this population will be just as important as pharmacological therapy. Further studies are needed in older seniors, especially men, to better understand the risks and benefits of pharmacologic therapy for the management of osteoporosis. 


\section{Disclosures}

The authors have no conflicts of interest to disclose.

\section{References}

1. Kanis JA. Diagnosis of osteoporosis and assessment of fracture risk. Lancet. 2002;359(9321):1929-1936.

2. National Health and Nutrition Examination Survey Osteoporosis Data Brief 12/02. Osteoporosis. Department of Health and Human Services. Centers for Disease Control and Prevention.National Center for Health Statistics. [Cited 2009 Jan 9.] Available from: http://www. cdc.gov/nchs/data/nhanes/databriefs/osteoporosis.pdf

3. Looker AC, Johnston CC Jr, Wahner HW, et al. Prevalence of low femoral bone density in older US women from NHANES III. $J$ Bone Miner Res. 1995;10(5):796-802.

4. He W, Manisha Sengupta, Vicotoria A. Velkoff, and Kimberly A. DeBarrows, US Census Bureau, Current Population Reports, P-23-209, 65+ in the United States: 2005, US Government Printing Office, Washington, DC, 2005.

5. Clinician's Guide to Prevention and Treatment of Osteoporosis. Washington DC: National Osteoporosis Foundation; c2008 [updated 2008 Feb 21; cited 2009 Jan 9]. Available from: http://www.nof.org/ professionals/NOF_Clinicians_Guide.pdf.

6. Facts and statistics about osteoporosis and its impact. International Osteoporosis Foundation; c 1999-2007; cited 2009 Jan 9. Available from: http://www.iofbonehealth.org/facts-and-statistics.html.

7. Cooper C, Atkinson EJ, O'Fallon WM, Melton LJ, 3rd. Incidence of clinically diagnosed vertebral fractures: a population-based study in Rochester, Minnesota, 1985-1989. J Bone Miner Res. 1992;7(2):221-227.

8. Cummings SR, Nevitt MC, Browner WS, et al. Risk factors for hip fracture in white women. Study of Osteoporotic Fractures Research Group. N Engl J Med. 1995;332(12):767-773.

9. Jacobsen SJ, Goldberg J, Miles TP, Brody JA, Stiers W, Rimm AA. Hip fracture incidence among the old and very old: a population-based study of 745,435 cases. Am J Public Health. 1990;80(7):871-873.

10. Kozak LJ, DeFrances CJ, Hall MJ. National hospital discharge survey: 2004 annual summary with detailed diagnosis and procedure data. Vital Health Stat 13. 2006;(162):1-209.

11. Wolinsky FD, Fitzgerald JF, Stump TE. The effect of hip fracture on mortality, hospitalization, and functional status: a prospective study. Am J Public Health. 1997;87(3):398-403.

12. Leibson CL, Tosteson AN, Gabriel SE, Ransom JE, Melton LJ. Mortality, disability, and nursing home use for persons with and without hip fracture: a population-based study. J Am Geriatr Soc. 2002;50(10):1644-1650.

13. Greendale GA, Barrett-Connor E, Ingles S, Haile R. Late physical and functional effects of osteoporotic fracture in women: the Rancho Bernardo Study. J Am Geriatr Soc. 1995;43(9):955-961.

14. Kado DM, Browner WS, Palermo L, Nevitt MC, Genant HK, Cummings SR. Vertebral fractures and mortality in older women: a prospective study. Study of Osteoporotic Fractures Research Group. Arch Intern Med. 1999;159(11):1215-1220.

15. Johnell O, Kanis JA, Oden A, et al. Mortality after osteoporotic fractures. Osteoporos Int. 2004;15(1):38-42.

16. Magaziner J, Lydick E, Hawkes W, et al. Excess mortality attributable to hip fracture in white women aged 70 years and older. Am J Public Health. 1997;87(10):1630-1636.

17. Trombetti A, Herrmann F, Hoffmeyer P, Schurch MA, Bonjour JP, Rizzoli R. Survival and potential years of life lost after hip fracture in men and age-matched women. Osteoporos Int. 2002;13(9):731-737.

18. Freedman KB, Kaplan FS, Bilker WB, Strom BL, Lowe RA. Treatment of osteoporosis: are physicians missing an opportunity? J Bone Joint Surg Am. 2000;82-A(8):1063-1070.

19. Parikh S, Mogun H, Avorn J, Solomon DH. Osteoporosis medication use in nursing home patients with fractures in 1 US state. Arch Intern Med. 2008;168(10):1111-1115.
20. Perreault S, Dragomir A, Desgagne A, et al. Trends and determinants of antiresorptive drug use for osteoporosis among elderly women. Pharmacoepidemiol Drug Saf. 2005;14(10):685-695.

21. Neuner JM, Zimmer JK, Hamel MB. Diagnosis and treatment of osteoporosis in patients with vertebral compression fractures. J Am Geriatr Soc. 2003;51(4):483-491.

22. Jachna CM, Shireman TI, Whittle J, Ellerbeck EF, Rigler SK. Differing patterns of antiresorptive pharmacotherapy in nursing facility residents and community dwellers. J Am Geriatr Soc. 2005;53(8):1275-1281.

23. Colon-Emeric C, Lyles KW, Levine DA, et al. Prevalence and predictors of osteoporosis treatment in nursing home residents with known osteoporosis or recent fracture. Osteoporos Int. 2007;18(4):553-559.

24. Wright RM. Use of osteoporosis medications in older nursing facility residents. J Am Med Dir Assoc. 2007;8(7):453-457.

25. Bouxsein ML. Determinants of skeletal fragility. Best Pract Res Clin Rheumatol. 2005;19(6):897-911.

26. Close JC, Lord SL, Menz HB, Sherrington C. What is the role of falls? Best Pract Res Clin Rheumatol. 2005;19(6):913-935.

27. Schwartz AV, Nevitt MC, Brown BW, Jr, Kelsey JL. Increased falling as a risk factor for fracture among older women: the study of osteoporotic fractures. Am J Epidemiol. 2005;161(2):180-185.

28. Sambrook PN, Cameron ID, Chen JS, et al. Influence of fall related factors and bone strength on fracture risk in the frail elderly. Osteoporos Int. 2007;18(5):603-610.

29. Centers for Disease Control and Prevention, National Center for Injury Prevention and Control. Web-based Injury Statistics Query and Reporting System (WISQARS) [online]. (2006) [updated 2008 Nov 18; cited 2009 Jan 9]. Available from: www.cdc.gov/ncipc/wisqars.

30. Grisso JA, Kelsey JL, Strom BL, et al. Risk factors for falls as a cause of hip fracture in women. The Northeast Hip Fracture Study Group. N Engl J Med. 1991;324(19):1326-1331.

31. Spector W, Shaffer T, Potter DE, Correa-de-Araujo R, Rhona Limcangco M. Risk factors associated with the occurrence of fractures in US nursing homes: resident and facility characteristics and prescription medications. J Am Geriatr Soc. 2007;55(3):327-333.

32. Cumming RG. Epidemiology of medication-related falls and fractures in the elderly. Drugs Aging. 1998;12(1):43-53.

33. Wei TS, Hu CH, Wang $\mathrm{SH}$, Hwang KL. Fall characteristics, functional mobility and bone mineral density as risk factors of hip fracture in the community-dwelling ambulatory elderly. Osteoporos Int. 2001;12(12):1050-1055.

34. Nevitt MC, Cummings SR. Type of fall and risk of hip and wrist fractures: the study of osteoporotic fractures. The Study of Osteoporotic Fractures Research Group. J Am Geriatr Soc. 1993;41(11): $1226-1234$

35. Holick MF. Vitamin D deficiency. N Engl J Med. 2007;357(3): 266-281.

36. Hamid Z, Riggs A, Spencer T, Redman C, Bodenner D. Vitamin D deficiency in residents of academic long-term care facilities despite having been prescribed vitamin D. J Am Med Dir Assoc. 2007;8(2):71-75.

37. Linnebur SA, Vondracek SF, Vande Griend JP, Ruscin JM, McDermott MT. Prevalence of vitamin D insufficiency in elderly ambulatory outpatients in Denver, Colorado. Am J Geriatr Pharmacother. 2007;5(1):1-8.

38. Lips P. Vitamin D deficiency and secondary hyperparathyroidism in the elderly: consequences for bone loss and fractures and therapeutic implications. Endocr Rev. 2001;22(4):477-501.

39. Sahota O, Masud T, San P, Hosking DJ. Vitamin D insufficiency increases bone turnover markers and enhances bone loss at the hip in patients with established vertebral osteoporosis. Clin Endocrinol (Oxf). 1999;51(2):217-221.

40. Janssen HCJP, Samson MM, Verhaar HJJ. Vitamin D deficiency, muscle function, and falls in elderly people. Am J Clin Nutr. 2002;75(4): 611-615.

41. Stein MS, Wark JD, Scherer SC, et al. Falls relate to vitamin D and parathyroid hormone in an Australian nursing home and hostel. J Am Geriatr Soc. 1999;47(10):1195-1201. 
42. US Department of Health and Human Services. Bone health and osteoporosis: a report of the Surgeon General In: Rockville, MD: US Department of Health and Human Services, Office of the Surgeon General; 2004:1-436.

43. Schousboe JT, Ensrud KE, Nyman JA, Melton LJ, 3rd, Kane RL. Universal bone densitometry screening combined with alendronate therapy for those diagnosed with osteoporosis is highly cost-effective for elderly women. J Am Geriatr Soc. 2005;53(10):1697-1704.

44. Schousboe JT, Taylor BC, Fink HA, et al. Cost-effectiveness of bone densitometry followed by treatment of osteoporosis in older men. JAMA. 2007;298(6):629-637.

45. Nelson HD, Helfand M, Woolf SH, Allan JD. Screening for postmenopausal osteoporosis: a review of the evidence for the US Preventive Services Task Force. Ann Intern Med. 2002;137(6):529-541.

46. Kanis JA, Burlet N, Cooper C, et al. European guidance for the diagnosis and management of osteoporosis in postmenopausal women. Osteoporos Int. 2008;19(4):399-428.

47. Baim S, Binkley N, Bilezikian JP, et al. Official Positions of the International Society for Clinical Densitometry and executive summary of the 2007 ISCD Position Development Conference. J Clin Densitom. 2008;11(1):75-91.

48. Neuner JM, Binkley N, Sparapani RA, Laud PW, Nattinger AB. Bone density testing in older women and its association with patient age. J Am Geriatr Soc. 2006;54(3):485-489.

49. King AB, Saag KG, Burge RT, Pisu M, Goel N. Fracture Reduction Affects Medicare Economics (FRAME): impact of increased osteoporosis diagnosis and treatment. Osteoporos Int. 2005;16(12): $1545-1557$.

50. Curtis JR, Carbone L, Cheng H, et al. Longitudinal trends in use of bone mass measurement among older americans, 1999-2005. J Bone Miner Res. 2008;23(7):1061-1067.

51. McNally DN, Kenny AM, Smith JA. Adherence of academic geriatric practitioners to osteoporosis screening guidelines. Osteoporos Int. 2007;18(2):177-183.

52. Juby AG. The use of calcaneal ultrasound evaluation of bone mineral density in cognitively impaired seniors. J Am Med Dir Assoc. 2004;5(6):377-381.

53. Krieg MA, Barkmann R, Gonnelli S, et al. Quantitative ultrasound in the management of osteoporosis: the 2007 ISCD Official Positions. J Clin Densitom. 2008;11:163-187.

54. Elliott ME, Drinka PJ, Krause P, Binkley NC, Mahoney JE. Osteoporosis assessment strategies for male nursing home residents. Maturitas. 2004;48(3):225-233.

55. Elliott ME, Binkley NC, Carnes M, et al. Fracture risks for women in long-term care: high prevalence of calcaneal osteoporosis and hypovitaminosis D. Pharmacotherapy. 2003;23(6):702-710.

56. FRAX WHO Fracture Risk Assessment Tool. University of Sheffield UK: World Health Organization Collaborating Centre for Metabolic Bone Diseases.; c2008 [cited 2009 Jan 9]. Available from: http://www. shef.ac.uk/FRAX/.

57. Ensrud KE, Black DM, Palermo L, et al. Treatment with alendronate prevents fractures in women at highest risk: results from the Fracture Intervention Trial. Arch Intern Med. 1997;157(22):2617-2624.

58. Guideline for the prevention of falls in older persons. American Geriatrics Society, British Geriatrics Society, and American Academy of Orthopaedic Surgeons Panel on Falls Prevention. J Am Geriatr Soc. 2001;49(5):664-672.

59. Chang JT, Ganz DA. Quality indicators for falls and mobility problems in vulnerable elders. J Am Geriatr Soc. 2007;55 Suppl 2:S327-S334.

60. Moylan KC, Binder EF. Falls in older adults: risk assessment, management and prevention. Am J Med. 2007;120(6):493 e1-e6.

61. Sinaki M. Nonpharmacologic interventions. Exercise, fall prevention, and role of physical medicine. Clin Geriatr Med. 2003;19(2):337-359.

62. Bonaiuti D SB, Iovine R, Negrini S, Robinson V, Kemper HC, Wells G, Tugwell P, Cranney A. Exercise for preventing and treating osteoporosis in postemenopausal women. Cochrane Database of Systematic Reviews; 2002(2).
63. Nelson ME, Rejeski WJ, Blair SN, et al. Physical activity and public health in older adults: recommendation from the American College of Sports Medicine and the American Heart Association. Med Sci Sports Exerc. 2007;39(8):1435-1445.

64. Bischoff-Ferrari HA, Dawson-Hughes B, Willett WC, et al. Effect of Vitamin D on falls: a meta-analysis. JAMA. 2004;291(16): 1999-2006.

65. Fosnight SM, Zafirau WJ, Hazelett SE. Vitamin D supplementation to prevent falls In the elderly: evidence and practical considerations. Pharmacotherapy. 2008;28(2):225-234.

66. Flicker L, MacInnis RJ, Stein MS, et al. Should older people in residential care receive vitamin $D$ to prevent falls? Results of a randomized trial. J Am Geriatr Soc. 2005;53(11):1881-1888.

67. Oncken C, Prestwood K, Kleppinger A, Wang Y, Cooney J, Raisz L. Impact of smoking cessation on bone mineral density in postmenopausal women. J Womens Health. 2006;15(10):1141-1150.

68. Cornuz J, Feskanich D, Willett WC, Colditz GA. Smoking, smoking cessation, and risk of hip fracture in women. Am J Med. 1999;106(3):311-314.

69. Sawka AM, Boulos P, Beattie K, et al. Do hip protectors decrease the risk of hip fracture in institutional and community-dwelling elderly? A systematic review and meta-analysis of randomized controlled trials. Osteoporos Int. 2005;16(12):1461-1474.

70. Kiel DP, Magaziner J, Zimmerman S, et al. Efficacy of a hip protector to prevent hip fracture in nursing home residents: the HIP PRO randomized controlled trial. JAMA. 2007;298(4):413-422.

71. O'Connell MB, Madden DM, Murray AM, Heaney RP, Kerzner LJ. Effects of proton pump inhibitors on calcium carbonate absorption in women: a randomized crossover trial. Am J Med. 2005;118(7):778-781.

72. Yang YX, Lewis JD, Epstein S, Metz DC. Long-term proton pump inhibitor therapy and risk of hip fracture. JAMA. 2006;296(24): 2947-2953.

73. Tang BMP, Eslick GD, Nowson C, Smith C, Bensoussan A. Use of calcium or calcium in combination with vitamin $\mathrm{D}$ supplementation to prevent fractures and bone loss in people aged 50 years and older: a meta-analysis. Lancet. 2007;370(9588):657-666.

74. Bischoff-Ferrari HA, Willett WC, Wong JB, Giovannucci E, Dietrich T, Dawson-Hughes B. Fracture prevention with vitamin D supplementation: a meta-analysis of randomized controlled trials. JAMA. 2005;293(18): 2257-2264.

75. Avenell A GW, Gillespie LD, O'Connell DL. Vitamin D and vitamin D analogues for preventing fractures associated with involutional and postmenopausal osteoporosis. Cochrane Database of Systematic Reviews; 2005(3)

76. Boonen S, Lips P, Bouillon R, Bischoff-Ferrari HA, Vanderschueren D, Haentjens P. Need for additional calcium to reduce the risk of hip fracture with vitamin d supplementation: evidence from a comparative metaanalysis of randomized controlled trials. J Clin Endocrinol Metab. 2007;92(4):1415-1423.

77. Broe KE, Chen TC, Weinberg J, Bischoff-Ferrari HA, Holick MF, Kiel DP. A higher dose of vitamin d reduces the risk of falls in nursing home residents: a randomized, multiple-dose study. J Am Geriatr Soc. 2007;55(2):234-239.

78. Law M, Withers H, Morris J, Anderson F. Vitamin D supplementation and the prevention of fractures and falls: results of a randomised trial in elderly people in residential accommodation. Age Ageing. 2006;35(5):482-486.

79. Lyons RA, Johansen A, Brophy S, et al. Preventing fractures among older people living in institutional care: a pragmatic randomised double blind placebo controlled trial of vitamin D supplementation. Osteoporos Int. 2007;18(6):811-818.

80. National Osteoporosis Guideline Group. World Health Organization Collaborating Centre for Metabolic Bone Diseases, University of Sheffield, UK. Guideline for the diagnosis and management of osteoporosis in postmenopausal women and men from the age of 50 years in the UK; 2008. [cited 2009 Jan 9]; Available from: http://www.shef.ac.uk/ NOGG/. 
81. Black DM, Cummings SR, Karpf DB, et al. Randomised trial of effect of alendronate on risk of fracture in women with existing vertebral fractures. Fracture Intervention Trial Research Group. Lancet. 1996;348(9041):1535-1541.

82. US Food and Drug Administration. Center for Drug Evaluation and Research. FDA Alert: Information on Bisphosphonates[created: 2008 Jan 7, updated 2008 Nov 12; cited 2009, Jan]. Available from: http:// www.fda.gov/cder/drug/infopage/bisphosphonates/default.htm.

83. Woo SB, Hellstein JW, Kalmar JR. Narrative review: bisphosphonates and osteonecrosis of the jaws. Ann Intern Med 2006;144(10): 753-761.

84. Krueger CD, West PM, Sargent M, Lodolce AE, Pickard AS. Bisphosphonate-induced osteonecrosis of the jaw. Ann Pharmacother. 2007;41(2):276-284.

85. US Food and Drug Administration. Center for Drug Evaluation and Research. Update of Safety Review Follow-up to the October 1, 2007 Early Communication about the Ongoing Safety Review of Bisphosphonates [created: 2008 Nov 12; cited 2009, Jan]. Available from: http://www.fda.gov/cder/drug/early_comm/bisphosphonates_update_ 200811.htm.

86. Papapoulos SE, Quandt SA, Liberman UA, Hochberg MC, Thompson DE. Meta-analysis of the efficacy of alendronate for the prevention of hip fractures in postmenopausal women. Osteoporos Int. 2005;16(5):468-474.

87. Reginster J, Minne HW, Sorensen OH, et al. Randomized trial of the effects of risedronate on vertebral fractures in women with established postmenopausal osteoporosis. Vertebral Efficacy with Risedronate Therapy (VERT) Study Group. Osteoporos Int. 2000;11(1):83-91.

88. McClung MR, Geusens P, Miller PD, et al. Effect of risedronate on the risk of hip fracture in elderly women. Hip Intervention Program Study Group. N Engl J Med. 2001;344(5):333-340.

89. Harris ST, Watts NB, Genant HK, et al. Effects of risedronate treatment on vertebral and nonvertebral fractures in women with postmenopausal osteoporosis: a randomized controlled trial. Vertebral Efficacy With Risedronate Therapy (VERT) Study Group. JAMA. 1999;282(14): 1344-1352.

90. Chesnut IC, Skag A, Christiansen C, et al. Effects of oral ibandronate administered daily or intermittently on fracture risk in postmenopausal osteoporosis. J Bone Miner Res. 2004;19(8):1241-1249.

91. Delmas PD, Adami S, Strugala C, et al. Intravenous ibandronate injections in postmenopausal women with osteoporosis: one-year results from the dosing intravenous administration study. Arthritis Rheum. 2006;54(6):1838-1846.

92. Lyles KW, Colon-Emeric CS, Magaziner JS, et al. Zoledronic acid and clinical fractures and mortality after hip fracture. $N$ Engl $J$ Med. 2007;357(18):1799-1809.

93. Black DM, Delmas PD, Eastell R, et al. Once-yearly zoledronic acid for treatment of postmenopausal osteoporosis. $N$ Engl J Med. 2007;356(18):1809-1822.

94. Ettinger B, Black DM, Mitlak BH, et al. Reduction of vertebral fracture risk in postmenopausal women with osteoporosis treated with raloxifene: results from a 3-year randomized clinical trial. Multiple Outcomes of Raloxifene Evaluation (MORE) Investigators. JAMA. 1999;282(7):637-645.

95. Barrett-Connor E, Mosca L, Collins P, et al. Effects of raloxifene on cardiovascular events and breast cancer in postmenopausal women. N Engl J Med. 2006;355(2):125-137.

96. Wooltorton E. Osteoporosis treatment: raloxifene (Evista) and stroke mortality. CMAJ. 2006;175(2):147.

97. Chesnut $\mathrm{CH}, 3$ rd, Silverman S, Andriano K, et al. A randomized trial of nasal spray salmon calcitonin in postmenopausal women with established osteoporosis: the prevent recurrence of osteoporotic fractures study. PROOF Study Group. Am J Med. 2000;109(4):267-276.

98. Knopp JA, Diner BM, Blitz M, Lyritis GP, Rowe BH. Calcitonin for treating acute pain of osteoporotic vertebral compression fractures: a systematic review of randomized, controlled trials. Osteoporos Int. 2005;16(10):1281-1290.
99. Neer RM, Arnaud CD, Zanchetta JR, et al. Effect of parathyroid hormone (1-34) on fractures and bone mineral density in postmenopausal women with osteoporosis. $N$ Engl J Med. 2001;344(19): 1434-1441.

100. Greenspan SL, Bone HG, Ettinger MP, et al. Effect of recombinant human parathyroid hormone (1-84) on vertebral fracture and bone mineral density in postmenopausal women with osteoporosis: a randomized trial. Ann Intern Med. 2007;146(5):326-339.

101. Meunier PJ, Roux C, Seeman E, et al. The effects of strontium ranelate on the risk of vertebral fracture in women with postmenopausal osteoporosis. N Engl J Med. 2004;350(5):459-468.

102. Reginster JY, Seeman E, De Vernejoul MC, et al. Strontium ranelate reduces the risk of nonvertebral fractures in postmenopausal women with osteoporosis: Treatment of Peripheral Osteoporosis (TROPOS) study. J Clin Endocrinol Metab. 2005;90(5):2816-2822.

103. O'Donnell S, Cranney A, Wells GA, Adachi JD, Reginster JY. Strontium ranelate for preventing and treating postmenopausal osteoporosis. Cochrane Database Syst Rev. 2006;(4):CD005326.

104. Anderson GL, Limacher M, Assaf AR, et al. Effects of conjugated equine estrogen in postmenopausal women with hysterectomy: the Women's Health Initiative randomized controlled trial. JAMA 2004;291(14):1701-1712.

105. Cauley JA, Robbins J, Chen Z, et al. Effects of estrogen plus progestin on risk of fracture and bone mineral density: the Women's Health Initiative randomized trial. JAMA. 2003;290(13):1729-1738.

106. Arias, E. National Vitals Statistic Report: United States Life Tables, 2003. Department of Health and Human Services. Centers for Disease Control and Prevention. National Center for Health Statistics. [created 2006 April 16, updated 2007 March 28; cited 2009 Jan 9] Available from: http://www.cdc.gov/nchs/data/statab/lewk3_2003.pdf.

107. Maricic M, Adachi JD, Sarkar S, Wu W, Wong M, Harper KD. Early effects of raloxifene on clinical vertebral fractures at 12 months in postmenopausal women with osteoporosis. Arch Intern Med. 2002;162(10):1140-1143.

108. Roux C, Seeman E, Eastell R, et al. Efficacy of risedronate on clinical vertebral fractures within six months. Curr Med Res Opin. 2004;20(4):433-439.

109. Hochberg MC, Thompson DE, Black DM, et al. Effect of alendronate on the age-specific incidence of symptomatic osteoporotic fractures. J Bone Miner Res. 2005;20(6):971-976.

110. Boonen S, McClung MR, Eastell R, El-Hajj Fuleihan G, Barton IP, Delmas P. Safety and efficacy of risedronate in reducing fracture risk in osteoporotic women aged 80 and older: implications for the use of antiresorptive agents in the old and oldest old. J Am Geriatr Soc. 2004;52(11):1832-1839.

111. Cauley JA, Black D, Boonen SR, et al. Effect of Zoledronic acid (ZOL) $5 \mathrm{mg}$ on fracture risk by age and geographic region in women with postmenopausal osteoporosis: results from HORIZON-PFT. Osteoporos Int. 2007;18 (Suppl 2):S232. Abstract from the Seventh International Symposium on Osteoporosis: Translating Research into Clinical Practice. \#P8.32.

112. Boonen S, Marin F, Mellstrom D, et al. Safety and efficacy of teriparatide in elderly women with established osteoporosis: bone anabolic therapy from a geriatric perspective. $J$ Am Geriatr Soc. 2006;54(5):782-789.

113. Marcus R, Wang O, Satterwhite J, Mitlak B. The skeletal response to teriparatide is largely independent of age, initial bone mineral density, and prevalent vertebral fractures in postmenopausal women with osteoporosis. J Bone Miner Res. 2003;18(1):18-23.

114. Seeman E, Vellas B, Benhamou C, et al. Strontium ranelate reduces the risk of vertebral and nonvertebral fractures in women eighty years of age and older. J Bone Miner Res. 2006;21(7):1113-1120.

115. Greenspan SL, Schneider DL, McClung MR, et al. Alendronate improves bone mineral density in elderly women with osteoporosis residing in long-term care facilities. A randomized, double-blind, placebo-controlled trial. Annals of Intern Med. 2002;136(10): $742-746$ 
116. Pun KK, Chan LW. Analgesic effect of intranasal salmon calcitonin in the treatment of osteoporotic vertebral fractures. Clin Ther. 1989;11(2):205-209.

117. Lyritis GP, Paspati I, Karachalios T, Ioakimidis D, Skarantavos G, Lyritis PG. Pain relief from nasal salmon calcitonin in osteoporotic vertebral crush fractures. A double blind, placebo-controlled clinical study. Acta Orthop Scand Suppl. 1997;275:112-114.

118. Orwoll ES, Scheele WH, Paul S, et al. The effect of teriparatide [human parathyroid hormone (1-34)] therapy on bone density in men with osteoporosis. J Bone Miner Res. 2003;18(1):9-17.

119. Sato Y, Iwamoto J, Kanoko T, Satoh K. Risedronate sodium therapy for prevention of hip fracture in men 65 years or older after stroke. Arch Intern Med. 2005;165(15):1743-1748.

120. Sato Y, Honda Y, Iwamoto J. Risedronate and ergocalciferol prevent hip fracture in elderly men with Parkinson disease. Neurology. 2007;68(12):911-915.

121. Ringe JD, Faber H, Farahmand P, Dorst A. Efficacy of risedronate in men with primary and secondary osteoporosis: results of a 1-year study. Rheumatol Int. 2006;26(5):427-431.

122. Finkelstein JS, Hayes A, Hunzelman JL, Wyland JJ, Lee H, Neer RM. The effects of parathyroid hormone, alendronate, or both in men with osteoporosis. N Engl J Med. 2003;349(13):1216-1226.

123. Orwoll E, Ettinger M, Weiss S, et al. Alendronate for the treatment of osteoporosis in men. N Engl J Med. 2000;343(9):604-610.

124. Ettinger MP, Felsenberg D, Harris ST, et al. Safety and tolerability of oral daily and intermittent ibandronate are not influenced by age. J Rheumatol. 2005;32(10):1968-1974.

125. Weycker D, Macarios D, Edelsberg J, Oster G. Compliance with osteoporosis drug therapy and risk of fracture. Osteoporos Int. 2007; 18(3):271-277.

126. Blouin J, Dragomir A, Moride Y, Ste-Marie LG, Fernandes JC, Perreault S. Impact of noncompliance with alendronate and risedronate on the incidence of nonvertebral osteoporotic fractures in elderly women. Br J Clin Pharmacol. 2008;66(1):117-127.

127. Siris ES, Harris ST, Rosen CJ, et al. Adherence to bisphosphonate therapy and fracture rates in osteoporotic women: relationship to vertebral and nonvertebral fractures from 2 US claims databases. Mayo Clin Proc. 2006;81(8):1013-1022.
128. Sorensen HT, Christensen S, Mehnert F, et al. Use of bisphosphonates among women and risk of atrial fibrillation and flutter: population based case-control study. BMJ. 2008;336(7648):813-816.

129. Cummings SR, Schwartz AV, Black DM. Alendronate and atrial fibrillation. N Engl J Med. 2007;356(18):1895-1896.

130. Heckbert SR, Li G, Cummings SR, Smith NL, Psaty BM. Use of alendronate and risk of incident atrial fibrillation in women. Arch Intern Med. 2008;168(8):826-831.

131. Vogel VG, Costantino JP, Wickerham DL, et al. Effects of tamoxifen vs raloxifene on the risk of developing invasive breast cancer and other disease outcomes: the NSABP Study of Tamoxifen and Raloxifene (STAR) P-2 trial. JAMA. 2006;295(23):2727-2741.

132. Clase CM, Garg AX, Kiberd BA. Prevalence of low glomerular filtration rate in nondiabetic Americans: Third National Health and Nutrition Examination Survey (NHANES III). J Am Soc Nephrol. 2002;13(5):1338-1349.

133. Jassal SK, von Muhlen D, Barrett-Connor E. Measures of renal function, BMD, bone loss, and osteoporotic fracture in older adults: the Rancho Bernardo study. J Bone Miner Res. 2007;22(2):203-210.

134. Miller PD, Roux C, Boonen S, Barton IP, Dunlap LE, Burgio DE. Safety and efficacy of risedronate in patients with age-related reduced renal function as estimated by the Cockcroft and Gault method: a pooled analysis of nine clinical trials. J Bone Miner Res. 2005;20(12):2105-2115.

135. Miller PD, Schwartz EN, Chen P, Misurski DA, Krege JH. Teriparatide in postmenopausal women with osteoporosis and mild or moderate renal impairment. Osteoporos Int. 2007;18(1):59-68.

136. Jamal SA, Bauer DC, Ensrud KE, et al. Alendronate treatment in women with normal to severely impaired renal function: an analysis of the fracture intervention trial. J Bone Miner Res. 2007;22(4): 503-508.

137. Ishani A, Blackwell T, Jamal SA, Cummings SR, Ensrud KE. The effect of raloxifene treatment in postmenopausal women with CKD. J Am Soc Nephrol. 2008;19(7):1430-1438. 